Gut, 1981, 22, 575-578

\title{
Changes in glucose tolerance after endoscopic retrograde cholangiopancreatography
}

\author{
Z TULASSAY, ${ }^{*}$ J PAPP, M SZATHMÁRI, S KISFALUDY, L KORÁNYI, AND G TAMÁS \\ From the Medical Clinic and Endoscopic Centre of Semmelweis University, Budapest
}

SUMMARY Changes in oral glucose tolerance have been studied in patients subjected to endoscopic retrograde pancreatography. Glucose tolerance is impaired 72 hours after ductography, and significant changes can still be seen even after one month; glucose tolerance returns to normal six to 12 months after pancreatography. In an attempt to discover the mechanism underlying impaired tolerance serial measurements were made of plasma insulin and glucagon levels. The observation that the ratio $\mathrm{I} / \mathrm{G}$ decreased in these patients indicates that enhanced glucagon release, probably due to mechanical and/or osmotic injury, may be responsible for the hyperglycaemia that is observed.

Endoscopic retrograde cholangiopancreatography (ERCP) has in the last few years become the most important diagnostic procedure in morphological abnormalities of the pancreas, particularly in cases where surgical correction is envisaged. The risks of the procedure have been outlined in studies involving a great number of patients. ${ }^{12}$ The short-lived functional alterations that follow the filling of the pancreatic duct with a radiographic contrast medium have also been studied. ${ }^{13}$ It is still unresolved, however, whether in the absence of clinical or biochemical manifestations there occur subtle abnormalities in the pancreas that are detectable by repeated investigations over a longer period of time. Whether ductography affects the function of the islet cells has not been settled either. The present study was undertaken to clarify some of these problems.

\section{Methods}

The technique of ERCP has been described in detail previously. ${ }^{2}$ Premedication consisted of pharyngeal anaesthestia with xylocaine spray (Lidocaine) and the intravenous administration of $100 \mathrm{mg}$ pethidine and $0.5 \mathrm{mg}$ atropine; diatrizoate $60 \%$ (Uromiro $^{\mathrm{R}}$, Bracco Ltd, Milan) was used as a radio-opaque medium. The total amount of radiographic contrast material delivered into the Wirsungian duct was also measured. Serum amylase levels were determined before and 10,

\footnotetext{
*Address for correspondence: Dr Z Tulassay. First Medical Clinic of Semmelweis University, Korányi 2/a, 1083 Budapest. Hungary.

Received for publication 28 January 1981
}

$20,30,40,60,90,120$, and 240 minutes, and six, 24 , and 48 hours after the ERCP. When evaluating the relationship between changes in glucose tolerance, amount of injected radioopaque medium, and the increase in serum amylase levels, values obtained at peak amylase values were considered, irrespective of the timing (Figure).

All patients exhibited normal morphology of the duct of Wirsung. In 10 cases bile duct abnormality could be also excluded, although ERCP had been indicated because of suggested biliary tract disease. The remaining five patients had cholelithiasis.

Oral glucose tolerance was studied, using a standard load of $50 \mathrm{~g}$, in 15 patients before and 72 hours, one, six, and 12 months after ERCP. With the exception of five patients who had gallstones, insulin and glucagon levels were established during the glucose tolerance test; of the 10 patients thus studied six had impaired, while four had normal, glucose tolerance.

Ten patients acted as controls (control I). They had previously been shown to have no abnormalities of carbohydrate metabolism and were not subjected to ERCP. In another 10 patients (control II), after a glucose tolerance test yielding normal results, upper panendoscopy was carried out using the same premedication as that described for ERCP. Glucose tolerance tests were repeated 72 hours and one month thereafter. Insulin was measured by the Boehringer insulin RIA test, glucagon by the $\mathrm{C}$ terminal (pancreatic glucagon) specific antibody, using standard radioimmunoassay techniques. ${ }^{4}$ The recommendations of the European Diabetic Associa- 
Figure Relationship between glucose tolerance, volume of radiographic medium injected and the maximum rise in serum amylase. $\bigcirc$ Glucose tolerance decreased. $\Delta$ Glucose tolerance unchanged.

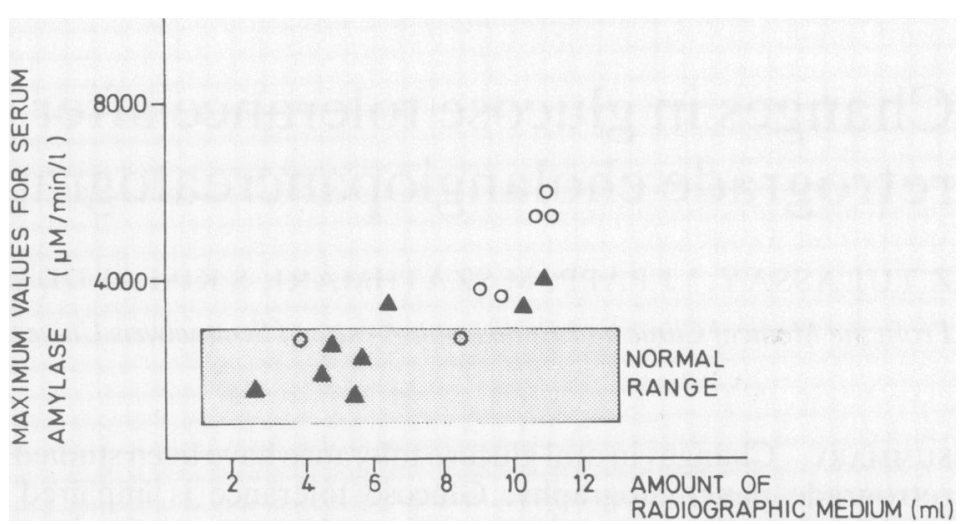

tolerance after ERCP (Table 1). All control subjects showed normal glucose tolerance 72 hours and one month after the first loading test. Thus the results are reproducible, neither premedication nor upper panendoscopy affecting per se the glucose tolerance of the patients.

Table 2 summarises the results obtained by planimetric analysis of the curves. There was a statistically significant increase of the area below the individual glucose tolerance curves 72 hours after pancreatography, while the results obtained after one month were not different from the initial values.

The data of planimetric analysis of the curves representing the changes in plasma insulin and glucagon levels during oral glucose loading have been also summarised in Table 2 . The glucose tolerance study performed 72 hours after pancreatography revealed enhanced release of both hormones, the increase in glucagon being substantially more marked; this accounts for the sharp drop in the ratio I/G, which was statistically significant. Repeated study after one month failed to reveal this differential response in pancreatic insulin and glucagon release. Impairment of glucose tolerance and the changes in I/G ratio are significantly correlated (at 72 hours: $r=0 \cdot 87, \mathrm{P}<0 \cdot 05$ ).

In five of the seven patients who showed impaired

Table 1 Oral glucose tolerance before and after ERCP in 15 patients followed over a period of 12 months

\begin{tabular}{|c|c|c|c|c|c|}
\hline & \multirow{2}{*}{$\begin{array}{l}\text { Before } \\
\text { ERCP }\end{array}$} & \multicolumn{4}{|c|}{ After $E R C P$} \\
\hline & & 72 hours & 1 month & 6 months & 12 months \\
\hline Normal glucose tolerance* & 15 & 8 & 11 & 15 & 15 \\
\hline Border-line curvest & 0 & 4 & 3 & 0 & 0 \\
\hline Impaired glucose tolerance $\ddagger$ & 0 & 3 & 1 & 0 & 0 \\
\hline
\end{tabular}

Blood glucose values/mmol/1/

\begin{tabular}{|c|c|c|}
\hline fasting & $60 \mathrm{~min}$ & $120 \mathrm{~min}$ \\
\hline $\begin{array}{l}\leqq 5 \cdot 50 \\
5 \cdot 5-7 \cdot 15\end{array}$ & $\begin{array}{l}\leqq \\
8 \cdot 80-12 \cdot 10\end{array}$ & $\begin{array}{l}\leqq 6 \cdot 60 \\
6.60-8 \cdot 25\end{array}$ \\
\hline$\geqq 7 \cdot 15$ & $\geqq 12 \cdot 10$ & $\geqq 8.25$ \\
\hline
\end{tabular}


Table 2 Planimetric analysis of glucose tolerance curves

\begin{tabular}{|c|c|c|c|c|c|c|c|c|c|}
\hline & \multirow[t]{2}{*}{$n$} & \multicolumn{2}{|c|}{ Before ERCP } & \multicolumn{3}{|c|}{ After 72 hours } & \multicolumn{3}{|c|}{ After 1 month } \\
\hline & & Mean & $S D$ & Mean & $S D$ & $\mathbf{P}<$ & Mean & $S D$ & $\mathbf{p}$ \\
\hline \multicolumn{10}{|c|}{ Patients subjected to ERCP } \\
\hline blood glucose & 15 & $742 \cdot 6$ & $98 \cdot 12$ & $854 \cdot 0$ & $163 \cdot 4$ & $0 \cdot 05$ & $787 \cdot 2$ & $118 \cdot 8$ & ns \\
\hline insulin & 10 & 60754 & 19325 & 78980 & 8506 & $0 \cdot 001$ & 68044 & 8506 & ns \\
\hline glucagon & 10 & 8377 & 3883 & 15079 & 3434 & $0 \cdot 001$ & 8796 & 4607 & ns \\
\hline I/G ratio & 10 & $7 \cdot 44$ & 0.91 & $5 \cdot 47$ & $0 \cdot 68$ & $0 \cdot 001$ & $7 \cdot 76$ & $2 \cdot 01$ & ns \\
\hline \multicolumn{10}{|l|}{ Control I patients } \\
\hline blood glucose & 10 & 726 & $72 \cdot 2$ & 704 & $43 \cdot 6$ & ns & 704 & $51 \cdot 0$ & ns \\
\hline \multicolumn{10}{|l|}{ Control II patients } \\
\hline blood glucose & 10 & $734 \cdot 7$ & $38 \cdot 3$ & 731 & $28 \cdot 5$ & ns & $755 \cdot 0$ & $27 \cdot 6$ & ns \\
\hline
\end{tabular}

glucose tolerance there was also a rise in serum amylase levels. Pathological serum amylase values were found in eight of the 15 patients subjected to pancreatography. The relationship between glucose tolerance, volume of the ractiographic contrast medium injected, and the maximum rise in serum amylase is shown in the Figure.

\section{Discussion}

Diminished glucose tolerance has been amply demonstrated to occur in acute pancreatitis. About $30 \%$ of patients with acute pancreatitis developed glycosuria, and raised blood glucose levels were found in about $50 \% .^{67}$ Blood glucose became normal after the acute phase of the disease had subsided; however, glucose tolerance was impaired for several weeks in $10 \%$ of the patients. ${ }^{6}$ Diabetes mellitus has been shown to persist in $2 \%$ of the patients after an episode of acute pancreatitis. ${ }^{8}$ Available data also indicate that, in the early phase of acute pancreatitis, impairment of glucose tolerance is due to abnormal functioning of the pancreatic alpha cells, while diabetes that develops after necrotising pancreatitis is the result of damaged beta cell function. ${ }^{69}$ It has been suggested by Adlung ${ }^{10}$ that acute pancreatitis is followed by relative insulin deficiency, the insulin present in the serum being part of the altered chemical structure and diminished biological activity.

Two per cent to $3 \%$ of patients subjected to ERCP develop acute pancreatitis. ${ }^{2}$ In view of the relationship between acute pancreatitis and diabetes mellitus there is a small but sizable number of patients who might become diabetic after such a study.

The frequency of biochemical abnormalities without clinical manifestations is much higher, about 40 to $50 \%$, after retrograde pancreatography. ${ }^{2}$ Thus about half of the patients will exhibit the laboratory changes usually observed in acute pancreatitis; these are, however, transient and are not accompanied by clinical symptoms. It seemed interesting to assess whether glucose tolerance was affected in such patients. Our results have shown that, 72 hours after retrograde pancreatography, a substantial number of patients exhibit impaired glucose tolerance. Marked changes in glucose tolerance may persist even one month after ERCP.

The most plausible explanation for the hyperglycaemia prevailing after retrograde pancreatography seems to be the increased glucagon release which is indicated by the changes in the insulin to glucagon ratio. This is in line with the suggestion made by Banks, ${ }^{4}$ who attributed the alterations in carbohydrate metabolism associated with acute pancreatitis to abnormal function of the alpha cells.

The extent of laboratory changes manifested in enzyme and hormone levels in the blood depends on the intraluminal pressure in the pancreatic ductthat is, the amount of radiographic medium injected. ${ }^{3}$ The data shown in the Figure indicate that there is a relationship between the impairment of glucose tolerance and the increase of intraluminal pressure. It is thus conceivable that the mechanical and osmotic challenge is transmitted also to the islet cells, resulting in impaired glucose tolerance. As the alpha cells have a more peripheral location in the pancreatic islets, it might be expected that glucagon release will be enhanced.

The importance of impaired glucose tolerance after retrograde pancreatography is evident in patients with diabetes. It should also be considered, however, in non-diabetic patients, particularly if other predisposing factors-for example, genetic ones-can be revealed. In such cases it seems appropriate, in addition to careful judgement of the indication for ERCP and more vigorous follow-up of the patient after study, to seek ways of preventing this development. 


\section{References}

${ }^{1}$ Caletti GC, Ventrucci M, Tomesani A, Verucchi G, Bolondi L, Labo G. Risk factors of acute pancreatitis after endoscopic retrograde cholangiopancreatography and endoscopic papillotomy. Acta Endosc 1979; 9: 271-80.

${ }^{2}$ Cotton PB. Progress report: ERCP. Gut 1977; 18: 316-41. ${ }^{3}$ Tamas G, Safrany L. Blood glucose, insulin and amylase levels in pancreatic lesion due to pancreatography. Acta Diabetol Lat 1973; 10: 518-33.

${ }^{4}$ Korányi L, Péterfy F, Paksy A, Vargha P. Production of glucagon antibodies by thyreoglobulin-zinc glucagon conjugate. Horm Metab Res 1977; 9: 434-5.

${ }^{5}$ Report of The European Diabetes Epidemiology Study Group. Diabetologia 1970; 6: 646-7.
${ }^{6}$ Bank S, Marks IN, Vinik AI. Clinical and hormonal aspects of pancreatic diabetes. Am J Gastroenterol 1975; 64: 13-22.

'Forell MM. Pankreas. Handbuch der inneren Medizin. 5. ed. Berlin: Springer, 1976.

${ }^{8}$ Gambill EE. Pancreatitis. Mosby: St Louis, 1973.

${ }^{9}$ Banks PA. Acute pancreatitis. Gastroenterology 1971; 61: 382.

${ }^{10}$ Adlung J, Koch C, Ritter U. Kohlenhydrattoleranz, Insulinsekretion und Insulinempfindlichkeit bei der akuten Pankreatitis. Z Gastroenterol 1974; 12: 81-6.

"Banks PA, Janowitz HD. Some metabolic aspects of exocrine pancreatic disease. Gastroenterology 1969; 56: 601-17. 